\title{
Koro-Like Syndrome in an Iranian 50 Years Old Man; Is It A Variant Caused by Cultural Issues?
}

\begin{abstract}
Keywords: Koro-like syndrome; Culture-bound syndrome; Dhat; Psychiatry

Abstract

Koro syndrome is a psychiatric disorder characterized by acute anxiety of one's genital retraction. In this culture-bound syndrome, originally reported in south and East Asia, the male individual believes that his penis is shrinking and deeply fears from its retraction into the abdomen and the resulted death. Here in this report we describe a patient of age 50 as first Iranian diagnosed with koro-like syndrome. He presented with the belief that his penis is shrinking gradually for the last three months and a persistent fear that it will subsequently be lost. He also reported Benign Prostatic Hyperplasia (BPH) which he refused treatment with Tamsulosin because of the fear that it would affect his penis and make it smaller. Compared to previously reported Koro symptoms, our patient reveals those characterized as main Koro features except for the fear of death with an addition al manifestation attributed to another culture-bound syndrome called "Dhat". The case was found to be a variant of Koro that is not described before in literature. More attention could help us better understand the syndrome.
\end{abstract}

\section{Introduction}

The typical form of Koro syndrome, which is a psychiatric disorder, more common in men, includes intense anxiety of a shrinking penis and its retraction into the abdomen resulting in death [1]. Existing in various races, cultures and religious groups of Asian and African countries, the syndrome found to be more common in traditions where reproductive ability is a major importance of young generation [2]. The term Koro-like syndrome or atypical Koro is used to describe non-Asians cases or those lacking certain symptoms of the typical Koro disorder. The comorbidity of Koro with other psychiatric disorders including schizophrenia, depression, body dysmorphic disorder and depersonalization has been reported [3-9]. The knowledge of Koro diagnosis and its cure management is critical for providing the proper care to the patients [10]. Here in this report, we introduce an Iranian case report of Koro-like syndrome and evaluate it based on other literature reported studies.

\section{Case Presentation}

A 50-year-old married man was admitted to our hospital in October 2016 suffering from deep fear that his penis is shrinking gradually for the last three months and will subsequently be lost. He described a strong continues anxiety and a subsequent insomnia during the past three months. Panicked by the feeling that his penis is shrinking back, the patient began to concern that it's even lost. Prior to the appearance of these symptoms, a urological surgery was performed on his son diagnosed with Hypospadias. The urologist warned him not to circumcise his son before surgery. Afterward, he started to feel

\section{Journal of}

Neurology and Psychology

\section{Mandana Haghshenas ${ }^{1}$, Farzaneh Malekpour ${ }^{1}$, Elaheh Yousefi', Mohammardreza Shalbafan ${ }^{1 *}$ Negar Behtash ${ }^{2}$ and Elham Shirazi ${ }^{3}$}

${ }^{\prime}$ Mental Health Research Center, Iran University of Medical Sciences, Tehran, Iran

${ }^{2}$ Urology Research Center, Sina Hospital, Tehran University of Medical Sciences, Tehran, Iran

${ }^{3}$ Mental Health Research Center, School of Behavioral Sciences and Mental Health, Iran University of Medical Sciences, Tehran, Iran

\section{*Address for Correspondence}

Mohammardreza Shalbafan, Mental Health Research Center, Iran University of Medical Sciences, Tehran Psychiatry Institute, No1, Mansoori Ave., Sattarkhan St., Tehran, Iran, Tel: +982166551665; E-mail: shalbafan.mr@iums.ac.ir

Submission: 09 March, 2017

Accepted: 29 March, 2017

Published: 05 April, 2017

Copyright: $\odot 2016$ Shalbafan M, et al. This is an open access article distributed under the Creative Commons Attribution License, which permits unrestricted use, distribution, and reproduction in any medium, provided the original work is properly cited.

anxious with the thought that he has a problem in his penis due to his early childhood circumcision. Consequently, he stated that he has a testicular cancer, after proper urological consideration the patient was diagnosed with Benign Prostatic Hyperplasia (BPH). The patient refused to take the prescribed Tamsulosin for his BPH treatment believing the drug would enhance urination and subsequently cause his penis to shrink in size. He was suffering from anxiety symptoms such as palpitation, perspiration, and obsessional thoughts about losing of his penis. He stated that all of symptoms initiated after his intensive fear of his penis shrinkage he had initial insomnia, loss of appetite, decreased libido, and dysphoric mood.

Based on hispsychiatric history, he was hospitalized fifteen years earlier diagnosed with a major depressive disorder. Moreover, his medical records show recent $\mathrm{BPH}$ and diabetes mellitus diagnosis. No significant history of drug and substance consumption was recorded in his medical history. There was no heritability history of psychiatric illness in his family. The patient stated that as a child he was shy often without any friends and not functioning well at school. However, we lack a reliable source of his personal history.

He was hospitalized for 40 days and started taking our prescribed medication as Fluvoxamine $100 \mathrm{mg} /$ twice per day, Perphenazine 4 mg/twice per day and Amantadine 100/twice per day. After forty days, his anxiety was reduced significantly along with the gradual improvement of his other symptoms. He was tested by a brain Magnetic Resonance Imaging (MRI) without contrast performed for him and no lesion or other abnormality was found in the results. His neurological evaluation confirmed the intact neurological pathways. We shared his manifestation with our internist and urologist colleagues, by whom the patient was visited in his third week of admission. Per our internal specialist's advice, we managed his 
Citation: Haghshenas M, Malekpour F, Yousefi E, Shalbafan M, Behtash N, et al. Koro-Like Syndrome in an Iranian 50 Years Old Man; Is It A Variant Caused by Cultural Issues?. J Neurol Psychol. 2017; 5(1): 3.

diabetes mellitus. Our urologist however reassured the patient that no real change in his penis size is happening. After her reassurance, the symptoms reduced dramatically and his fear disappeared till the discharge date.

\section{Discussion}

Koro is known to be a culture-bound syndrome with three main manifestations: the belief of a shrinking penis, anxiety about its disappearance in abdomen and fear of the resulting death [11-15]. Our patient shows two out of the three main characteristics of Koro, thinking that his penis is diminishing gradually and a persistent fear that it will subsequently be lost. However no sign of any fear related to a subsequent death was observed during his frequent interviews. Therefore, the case was not classified as classic Koro disorder. As mentioned earlier, the term Koro-like syndrome is attributed to patients with similar Koro characteristics and failing to meet all [15] Among reported Koro-like disorders there are a cannabis-induced Koro-like syndrome and a case showing intense fear of the tongue retraction and the resulting death $[15,16]$. Specially, most Koro related disorders reported in Western countries are described as Koro-like syndrome [17]. It is often impossible to distinguish Korolike syndrome manifestations, like our case, with early stage of Koro syndrome by cross-sectional observation. In those cases longitudinal observation and frequent interviews in substantial intervals seems to be helpful and discriminative.

On the other hand our patient presented an additional symptom than those of Koro. As stated earlier, the patient was diagnosed with $\mathrm{BPH}$ and Tamsulosin was prescribed for his treatment. He refused to take this medication believing that it can cause polyuria and therefore accelerates the shrinking process of his penis. This belief has not been reported in any typical Koro and Koro-like patients. However, the additional symptom can be attributed to another culture-bound syndrome called "Dhat". The syndrome, originally reported in India [18], is characterized by sever anxiety associated with semen-loss [19]. This culture-bound syndrome can cause fatigue, weakness, palpitation, and insomnia these signs and symptoms are similar to those of our patient's clinical record [20]. However no concern about the loss of semen was found in our case. This could be attributed to the cultural differences and more specifically a distinguished Iranian culture in which speaking of sexual concern is a taboo.

Though Koro was classified as a culture-bound psychosis, distinguished from Obsessive-Compulsive and Related Disorders in the past [21], the Diagnostic and Statistical Manual of mental disorders (DSM-5) has classified it as an example of "Other Specified Obsessive-Compulsive and Related Disorders" and described it related to Dhat [22]. Comparing our patient's symptoms with those of Obsessive-Compulsive and Related Disorders, we concluded that the case should not be considered psychotic. Our main reason is the dramatic response of the patient to the urological consultation. After our urologist colleague reassured the patient that no real change in his penis size is happening, a significant reduction in the patient's anxiety was resulted. As we know delusion is a belief that is incorrect and can't be changed by evidences [23].

\section{Conclusion}

Our case reveals a variant of Koro-like syndrome with some additional symptoms attributed to main characteristics of another culture-bound disorder, called "Dhat". The response of the patient to the urologist reassurance supports our conclusion in defining his presentation as an overvalued idea.

Nevertheless, larger number of case-reports and case series could be beneficial for understanding variants of Koro syndrome.

\section{References}

1. Sachdev PS (1985) Koro epidemic in north-east India. Aust N Z J Psychiatry 19: $433-438$

2. Mattelaer JJ, Jilek W (2007) Koro--the psychological disappearance of the penis. J Sex Med 4: 1509-1515.

3. Durst R, Rosca-Rebaudengo P (1991) The disorder named koro. Behav Neurol 4: 1-13

4. Chowdhury AN, Rajbhandari KC (1995) Koro with depression in Nepal. Transcultural Psychiatry 32: 87-90

5. Devan GS, Hong OS (1987) Koro and schizophrenia in Singapore. Br J Psychiatry 150: 106-107.

6. Fernando $\mathrm{N}$ (1988) Monosymptomatic hypochondriasis treated with a tricyclic antidepressant. Br J Psychiatry 152: 851-852.

7. Money J, Annecillo C (1987) Body-image pathology: Koro, the shrinkingpenis syndrome in transcultural sexology. J Sex Marital Ther 2: 91-100.

8. Walter G (1991) An unusual monosymptomatic hypochondriacal delusion presenting as self-insertion of a foreign body into the urethra. $\mathrm{Br} \mathrm{J}$ Psychiatry 159: 283-284.

9. Westermeyer $\mathrm{J}$ (1989) A case of koro in a refugee family: association with depression and folie a deux. J Clin Psychiatry 50: 181-183.

10. Silva L, Raposo-Lima C, Soares C, Cerqueira JJ, Morgado P (2016) Koro syndrome in an obsessive-compulsive disorder patient. Eur Psychiatry 33 Supplement: S618.

11. Sadock BJ, Sadock VA, Ruiz P, Kaplan HI (2009) Kaplan \& Sadock's Comprehensive Textbook of Psychiatry. Philadelphia : Wolters Kluwer Health/Lippincott Williams \& Wilkins, Vol 2

12. Chakraborty S, Sanyal D (2011) An outbreak of Koro among 19 workers in a jute mill in south Bengal. Ind Psychiatry J 20: 58-60.

13. Chowdhury AN (1996) The definition and classification of Koro. Cult Med Psychiatry 20: 41-65.

14. Witztum E, Bersudsky Y, Mayodovnik H, Kotler M (1998) Koro-like syndrome in a Bedouin man. Psychopathology 31: 174-177.

15. Chin CN, S'ng KH (1995) "Koro"-like syndrome affecting the tongue--a case report. Med J Malaysia 50: 175-177.

16. Kalaitzi CK, Kalantzis A (2006) Cannabis-induced koro-like syndrome. A case report and mini review. Urol Int 76: 278-280.

17. Ntouros E, Ntoumanis A, Bozikas VP, Donias S, Giouzepas I, et al. (2010) Koro-like symptoms in two Greek men. BMJ Case Rep 2010: 2010.

18. Prakash S, Sharan P, Sood M (2016) A study on phenomenology of Dhat syndrome in men in a general medical setting. Indian J Psychiatry 58: 129141.

19. Grover S, Gupta S, Avasthi A (2016) A follow-up study of patients with Dhat syndrome: Treatment pattern, outcome, and reasons for dropout from treatment. Indian J Psychiatry 58: 49-56.

20. Grover S, Gupta S, Mahajan S, Avasthi A (2016) Pathway of care among patients with Dhat syndrome attending a psychosexual clinic in tertiary care center in North India. Indian J Psychiatry J 25: 72-77. 
Citation: Haghshenas M, Malekpour F, Yousefi E, Shalbafan M, Behtash N, et al. Koro-Like Syndrome in an Iranian 50 Years Old Man; Is It A Variant Caused by Cultural Issues?. J Neurol Psychol. 2017; 5(1): 3.

ISSN: $2332-3469$

21. Sadock BJ, Sadock VA, Ruiz P (2015) Kaplan and Sadock's synopsis of psychiatry: behavioral sciences/clinical psychiatry. Lippincott Williams \& Wilkins.
22. American Psychiatric Association (2013) Diagnostic and statistical manual of mental disorders (DSM-5 ${ }^{\circledR}$ ). American Psychiatric Pub.

23. Oyebode F (2008) Sims' symptoms in the mind: an introduction to descriptive psychopathology. Elsevier Health Sciences.

\section{Acknowledgements}

The authors appreciate nursing team of Iran Psychiatry Hospital specially staffs of 2nd Men Ward and its head nurse "Zahra Ostovari" and family of our patient for their cooperation. 